\title{
Analysis on Efficiency and Its Influence Factors of Financial Support for Listed Companies of Guangdong New Energy Industry
}

\author{
Jixiang Liu ${ }^{1} \&$ Hongyan Liao ${ }^{1}$ \\ ${ }^{1}$ Finance Department of International Business School, Jinan University, Zhuhai, China \\ Correspondence: Hongyan Liao, Jinan University, No. 206, Qianshan Road, Xiangzhou District, Zhuhai, China. \\ Tel: 86-158-2058-1374. E-mail: 812602882@qq.com
}

Received: November 10, 2016

Accepted: December 1, 2016

Online Published: January 10, 2017

doi:10.5539/ijef.v9n2p70

URL: http://dx.doi.org/10.5539/ijef.v9n2p70

\begin{abstract}
The development of Guangdong new energy industry plays an important role in promoting the current process of economic restructuring in Guangdong province. As the core of modern economy, the financial system also has an important impact on the development of the new energy industry. This paper mainly employs DEA method to measure the efficiency of financial support of the new energy industry in Guangdong Province, and takes it as a core to establish an influence-factor model of financial support efficiency. Through empirical analysis, we can find the stability of Guangdong new energy industry insufficient; on the condition of indirect financing power shortage, the direct financing makes the flow of capital available, thus showing a more positive impact on the efficiency of financial support. According to the results, we should broaden the direct financing way of the new energy industry in Guangdong Province, reduce bank credit financing costs, promote diversified development of financial services, and improve the ability of the new energy industry against market risks.
\end{abstract}

Keywords: new energy industry, DEA model, the efficiency of financial support, co-integration, error correction model

\section{Introduction}

\subsection{Introduce the Problem}

On June 16, 2014, the Guangdong Provincial People's Government combined the requirements of "the State Council Guidance on Financial Support for economic Restructuring and Upgrading Transformation" and "the Decision of the State Council on Accelerating the Cultivation and Development of Strategic Emerging Industries" and other documents examined and adopted by the State Council executive meeting, and then further deepens financial reforms proposed in Guangdong province, to improve the financial market system, promote financial innovation and development, and comprehensively promote the construction of financial province. While promoting financial innovation and development, strong support for economic restructuring and industrial upgrading transformation is provided, which will promote the development of strategic emerging industries. Among them, according to the decision of the State Council executive meeting, the following industries are planned as the seventh important strategic emerging industries for current stage: energy saving, new generation of information technology, biotechnology, high-end equipment manufacturing, new energy, new materials and new energy vehicles (Chen, 2010). New energy industry, as a representative strategic emerging industry, will become one of the most focused industries to develop in Guangdong Province.

Moreover, this year, China issued a series of supportive policies to support the development of new energy sources, including accelerating the applications of solar PV to building, encouraging the wide application of solar energy in the construction field, and encouraging the development of new energy vehicles. Li Keqiang, our Vice Premier, also said last month that the new energy industry is giving birth to a new economic growth point, and China will actively promote nuclear power construction, develop new energy industries, and promote the adjustment of the energy industry or even the whole industry structure. Other countries and regions, including the United States, Europe, Australia and South Korea, have also invested heavily in this area, hoping to develop new energy sources as a new economic growth point.

The strategic new energy industry shows rapid development changes in the process of modernization, if it is going to develop as a new economic growth point, it cannot do without financial support. Finance not only 
promotes the overall development of the economy, but also plays an essential role in upgrading and adjusting the economic structure. To raise funds through financial will bring fresh blood and boundless energy into emerging industries. Finance is the central pillar of the strategic development of new industries, and its essence is the bridge for promoting the transformation from savings into investment, and the conversion channel for transforming the fund from the surplus sector to the shortage sector. The configuration of financial resources run a significant impact on economic situation and the operation effects of micro-enterprises, and plays a key role in production efficiency. Therefore, the level of financial efficiency will be an important factor in determining the development of the industry, which is also a key factor in improving regional economic competitiveness.

Economic development, as an artery of modern finance development, plays a fundamental and core supporting role in the process of strategic emerging industries. Financial support is the foundation of prosperity and development of strategic emerging industries; the efficiency of financial support of strategic emerging industries will become the key to determine the extent of the industrial boom. The development of strategic emerging industries is a comprehensive engineering system composed of financial support, resource support, technical support, management support, and many other support factors.

According to the "the State Council Guidance on Financial Support for economic Restructuring and Upgrading Transformation", since the Guangdong provincial government put forward the policy of economic restructuring and the upgrading transformation, it has been committed to promoting development of financial, technological and strategic emerging industries with innovational convergence, so as to this promote industrial upgrading. Based on DEA model, this paper analyzes the efficiency of the listed new energy companies' financial support among the strategic emerging industries of Guangdong province, aimed to provide a powerful way for financial support to the development of strategic new energy industries.

\subsection{Describe Relevant Scholarship}

At present, research on the financial support for new energy industries is divided into two aspects: firstly, study the relationship between finance and the development of new energy industries, and discuss the financial mechanisms to support its industrial development and its influencing factors; secondly, study how financial support measures efficiency of financial support, and establish a new system for impact assessment of energy industry development.

First of all, according to the mechanism of financial support for industrial development, the study (Mata \& Machado, 1996) has shown that the development degree of a country's financial system plays a positive role in promoting the country's industrial development, and the financial system can affect the industries with technical innovation characteristics, thus affecting the economic growth of the country. The empirical study (Schreft \& Smith, 1998) indicates a causal relationship between financial support and industrial development; Zhang (2006) draw the conclusion that financial development and financial support help to improve the industrial capital allocation efficiency. Then, many domestic scholars study the influencing factors of the financial support to the new energy industries, analyze the current financial support problems and made some recommendations. Zhang (2009) thought that, to promote the development of strategic emerging industries (including new energy industries), a wide range of financial support should be given in government policy and capital markets. Zhu, Xiao, and Chen (2009) argued that the supporting capital and scope of the political finance to the development of new energy industries are limited, while commercial finance can employ a variety of financing methods to meet the needs of the project development. Jiang, Wang, and Lv. (2010) noted that the existing financing ways of China's new energy industries have many limitations, and proposed that project financing, as a new way of financing, can provide financial support to new energy industries. Feng (2010) proposed a combination of policy and market-based finance, and a combination of direct financing and indirect financing, which would be beneficial to the adjustment of industrial structure. Liu and Yan (2013) noted that there is certain mismatch between the new energy industries as well as its financial needs and traditional financing patterns, resulting in the disadvantage of financial support for new energy development issues. Zhu, Hu, and Ding (2011) gave some advice in the new energy financial support that while the government fully shows its effects of guiding and promoting, we should carry out financial instruments innovation, establish a long-term mechanism of credit support and improve risk investment mechanism, so as to provide a good environment for the development of the energy industries. Starting from China's actual situation, Tan and Li (2012) believed that the emerging industries have special financing needs, and the current financial system is defective, therefore the innovation of bank credit model is needed, the capital market should be improved, the insurance mechanism of new strategic emerging industries should be developed, so as to transfer and disperse industrial risks. Overall, the current research on financial support for the development of new energy industries are mostly concentrated in the discussion on the importance of financial support for industrial development as well as the effective ways and 
channels of financial support, but relevant empirical research is relatively less. In addition, the research of current financial support for the new energy industries of Guangdong Province hardly exists, and the new energy industries are mostly contained in the study of new strategic emerging industries. Therefore, a separate research on the financial support efficiency of the new energy industries in Guangdong Province has special significance, which can provide reasonable recommendations to Guangdong provincial government.

Domestic scholars have also done a lot of related research on the measurement of support efficiency of new energy industries and the construction of the influence-factor model. The research mainly focuses on the measurement and analysis with the single use of DEA model, as well as the efficiency analysis with only metering regression model, but there is little research combined with DEA model and econometric model to carry out comprehensive analysis. Song and Zhang (2003) first proposed the concept of financing efficiency and allocative efficiency, introduced asset-liability ratio of listed companies, the proportion of tradable shares, corporate finance costs and Tobin's q value, and established the efficiency test model. Ma (2013) applied DEA-Tobit two-stage approach to measure the financial support efficiency of the seven strategic emerging industries in China, and analyzed its influencing factors. Li and Yin (2014) combined the features of strategic emerging industries in different periods. Based on the panel Granger causality test and co-integration analysis method, they established a model and analyzed the influence of the financial support on the strategic emerging industries. Zhao (2014) using the DEA model, analyzes the financial support efficiency of 41 Listed Companies of strategic emerging industries in Anhui, and made recommendations according to the conclusions. Xu and Zhou (2014) used DEA model and Logit model, studied the impact and the role of financial support for new energy industries based on the data of listed companies in new energy industries. Xu and Chen (2014) used the BCC-DEA model and DEA-Malmquist index model, took the data of 32 listed low-carbon companies during 2007-2013 as sample, and carried out empirical analysis on banking support efficiency of low-carbon industrial development from a cross-section dimension and the span longitudinal dimension. Yin, Wang, and Feng (2015) used the time series data during 2000-2013, carried out regression analysis on the new energy industry financial support in the financial scale, financial structure and financial efficiency through econometric model, and analyzed the promoting effect of the above factors on the development of new energy industries. Overall, the study integrating DEA and econometric models is not much. Therefore, considering from this perspective to study the financial support efficiency for new energy industries in Guangdong Province is available.

\section{Method}

\subsection{Financial Support Efficiency Evaluation Model - DEA model}

Data Envelopment Analysis (DEA) is an efficiency evaluation method developed by famous American Operational Research Expert A. Charnes and others based on the concept of relative efficiency. This method simply defines the process with single-input and single-output or the efficiency of decision making units as: Input/Output. A. Charnes and other experts promoted this idea to the analysis of the production on the validity of multi-input and multi-output. Similarly, they defined the process with multi-input and multi-output or the efficiency of decision making units as: weighted sum of the output terms/weighted sum of the input terms.

The features of DEA data envelopment analysis method is to form the evaluation system to solely rely on the analysis of input and output data of production Decision Making Units (DMU), so as to evaluate the relative effectiveness between the multiple-input Decision Making Units and multiple-output Decision Making Units. This evaluation system keeps input DMU or output DMU unchanged; by means of mathematical programming and statistical data, it determines the production frontier of the relative effectiveness and projects each DMU onto the surface of the DEA production frontier; it also evaluates their relative effectiveness by comparing the deviation degree of DMU from the DEA frontier.

DEA model uses parametric optimization programming to evaluate and analyze the relative effective degree of the system with multiple input and multiple output. BCC model used in this paper is a new constant variable based on the assumption in the CCR model that the constant value of the production function will return on the initial scale, in order to ensure the full return to former scale. Financial support for the new energy industries is characterized by more input and more output. Based on it, this paper uses BCC model to analyze the relative efficiency of the financial support of the new listed companies in Guangdong province and the returns according to industry scales.

This paper mainly studies the efficiency of fund raising and capital configuration. Fund raising efficiency refers to the ability of companies to finance through a variety of ways and instruments, minimize the cost of access to capital, so as to support business operations. Capital allocation efficiency refers to the ability of companies to apply the funds to production and operation activities, and maximize the output performance. According to the 
two characteristics of financial support efficiency, this paper respectively employs input-oriented BCC model and output-oriented BCC model to calculate the efficiency of fund raising and capital configuration.

\subsection{Selection of Input and Output Index}

While choosing the input and output indicators, this paper uses the two methods: production method and assets method. By studying from the previous results and considering the data availability, this paper decides to select Debt Ratio (DR) and Negotiable-share Ratio (NR) as the input indicators of the capital allocation efficiency analysis model. In addition, taking the market risk factors into account, this paper decided to introduce innovative risk factor (Beta) as a third input indicator. Wherein, DR can be used to measure the level of indirect financing, NR can be used to measure the level of direct financing, and Beta can be used to measure systemic risk. Considering that the development of enterprises is mainly measured through operating performance, therefore, the paper selected return on net assets and growth in total revenue as common output indicators of the efficiency of fund raising and capital configuration. Depending on the characteristics of fund-raising efficiency and capital allocation efficiency, this paper selected the total cost of enterprise as a third output indicator of fund raising efficiency, and select Tobin's q as a third output indicator of capital allocation efficiency.

\subsection{Data Sources}

Considering that the data of listed companies is public and continuous, this paper selects the studied objects from the new energy industry sector from GTA database, picks out 32 New Energy Listed Companies registered in Guangdong, and extracts the financial indicator data of the 24 quarters during 2010-2015 to carry out panel data analysis. To make the data meaningful, this paper excluded the companies with incomplete annual reports while selecting samples.

\subsection{Influence-Factor Regression Model of Efficiency}

Through the operation of DEA model, we can obtain the efficiency value of fund raising and capital configuration. In order to further study the relationship between financial support efficiency and various input indicators, this paper will carry out panel data regression analysis of financial support efficiency influence-factors. After the panel unit root test, we introduce Engle-Granger co-integration framework, namely to build long-term equilibrium model and short-term error correction model based on residual items. The Long-Term equilibrium model is:

$$
\text { Score }_{i t}=\alpha+\beta_{1} \text { Beta }_{i t}+\beta_{2} D R_{i t}+\beta_{3} N R_{i t}+\varepsilon_{i t}
$$

The short-term error correction model based on residual items is:

$$
D\left(\text { Score }_{i t}\right)=\alpha+\beta_{1} D\left(\text { Beta }_{i t}\right)+\beta_{2} D\left(D R_{i t}\right)+\beta_{3} D\left(N R_{i t}\right)+\lambda E C M_{i, t-1}+\varepsilon_{i t}
$$

Wherein, $E C M_{i, t-1}$ is the error correction term (i.e. the lagged residual item in long-run equilibrium relationship). If the explanatory variable coefficients in the long-term equilibrium model can pass the significant test, and the residual is a stationary sequence, then there is co-integration relationship between variables. In addition, if the statistic coefficient $E C M_{i, t-1}$ in short-term error correction model is significant, it can explain to have an error correction mechanism, making short-term bias controlled within a certain range, namely the existence of short-term causal relationship.

\section{Empirical Analysis}

\subsection{Efficiency and Fund-Raising Factors}

\section{1) Analysis on DEA Efficiency Measurement of Fund Raising}

The consideration of fundraising efficiency means the capacity that enterprises can minimize the cost of financing along with the given level of output. Therefore, this paper uses input-oriented DEA model to measure the fund-raising efficiency of the listed new energy companies in Guangdong Province, and through the analysis of BCC model in MAXDEA6 software, we obtain the fund-raising efficiency measurement results of new energy listed companies, which can be shown in the table below. Overall, the overall fund-raising technical efficiency of 32 new energy listed companies is 0.732 , the maximum value is 1 , and the minimum value is 0.435 . In terms of the overall trend, it starts at a relatively high level of efficiency value, and then decreases, after which it gradually rises. It can be seen that the fund-raising efficiency of the new energy industries has been volatile. During 2010, the State Council promulgated "the Decision of the State Council on Accelerating the Cultivation and Development of Strategic Emerging Industries", where the new energy industries are planned as one of the seven most important strategic emerging industries at this stage. New energy industry, as a representative strategic emerging industry, has become one of the most important industries to develop in Guangdong Province. Thus, under the support of national policy and the Guangdong Provincial Government in 2010, the new energy 
industry has relatively relaxing financing environment, the financing costs decline and financing channels increase, which makes the integrated technology of fund-raising efficiency in the new energy listed companies of Guangdong Province reach a higher level, remaining above 0.75 and reaching to the maximum efficiency in the fourth quarter of 2010. After 2011, the beneficial policy turns cold, investors' enthusiasm on the stocks of strategic emerging industries decline, the financing environment gets tight, financing channels shrink, which makes fund-raising efficiency decrease. At the same time, due to the international economic environment, the fund-raising efficiency of new energy industries shows large fluctuations, and the efficiency value reaches its lowest point in the second quarter of 2013. After that, new energy listed companies make their own industrial restructuring and improve financing strategies, and the Guangdong provincial government makes the decision to further deepen financial reform and improve financial markets, which makes the overall efficiency gradually increase and return to a higher level, and it reaches to the maximum as 1 in the second quarter of 2015. Moreover, from a pure technical efficiency point of view, the average is 0.78 , slightly higher than the overall efficiency, which indicates that the capacity of new energy listed companies in Guangdong to transform the technology into effective output is much stronger. Therefore, the improvement of technical efficiency is the main factor of increasing fund-raising efficiency. As for the scale of remuneration, in many quarters, Guangdong's new energy industries have increasing returns to scale in the production frontier, indicating the current scale of the new energy industries in Guangdong to raise funds from the market needs further expanding.

Table 1. DEA fund-raising efficiency value of the new energy industries in Guangdong province

\begin{tabular}{ccccc}
\hline \multirow{2}{*}{ Time } & \multicolumn{5}{c}{ New Energy Industries } \\
\cline { 2 - 5 } $\mathbf{2 0 1 0 Q 1}$ & Integrated Technical Efficiency & Pure Technical Efficiency & Scale Efficiency & Returns to scale \\
$\mathbf{2 0 1 0 Q 2}$ & 0.924568 & 0.945123 & 0.978252 & constant \\
$\mathbf{2 0 1 0 Q 3}$ & 0.809548 & 0.909263 & 0.890334 & increasing \\
$\mathbf{2 0 1 0 Q 4}$ & 0.925447 & 1 & 0.925447 & increasing \\
\hline $\mathbf{2 0 1 1 Q 1}$ & 1 & 1 & 1 & constant \\
$\mathbf{2 0 1 1 Q 2}$ & 0.936406 & 0.936406 & increasing \\
$\mathbf{2 0 1 1 Q 3}$ & 0.754163 & 0.800042 & 0.942654 & increasing \\
$\mathbf{2 0 1 1 Q 4}$ & 0.845172 & 0.987452 & 0.855912 & constant \\
\hline $\mathbf{2 0 1 2 Q 1}$ & 0.795606 & 0.940753 & 0.845712 & increasing \\
$\mathbf{2 0 1 2 Q 2}$ & 0.504994 & 0.504994 & 1 & increasing \\
$\mathbf{2 0 1 2 Q 3}$ & 0.496112 & 0.527757 & 0.940039 & increasing \\
$\mathbf{2 0 1 2 Q 4}$ & 0.610527 & 0.610527 & 1 & increasing \\
\hline $\mathbf{2 0 1 3 Q 1}$ & 0.674453 & 0.684675 & 0.985070 & increasing \\
$\mathbf{2 0 1 3 Q 2}$ & 0.464103 & 0.495064 & 0.937461 & increasing \\
$\mathbf{2 0 1 3 Q 3}$ & 0.435487 & 0.485826 & 0.896385 & increasing \\
$\mathbf{2 0 1 3 Q 4}$ & 0.524185 & 0.583266 & 0.898707 & increasing \\
\hline $\mathbf{2 0 1 4 Q 1}$ & 0.719452 & 0.745408 & 0.965179 & increasing \\
$\mathbf{2 0 1 4 Q 2}$ & 0.588568 & 0.634165 & 0.928099 & increasing \\
$\mathbf{2 0 1 4 Q 3}$ & 0.598746 & 0.641296 & 0.933650 & increasing \\
$\mathbf{2 0 1 4 Q 4}$ & 0.621641 & 0.690206 & 0.900660 & increasing \\
\hline $\mathbf{2 0 1 5 Q 1}$ & 0.88661 & 0.965487 & 0.918303 & increasing \\
$\mathbf{2 0 1 5 Q 2}$ & 0.946127 & 0.987456 & 0.958146 & increasing \\
$\mathbf{2 0 1 5 Q 3}$ & 1 & 1 & 1 & constant \\
$\mathbf{2 0 1 5 Q 4}$ & 0.645861 & 0.706174 & 0.914592 & decreasing \\
\hline
\end{tabular}

\section{2) Unit-Root Test of Variables in Fund-Raising Efficiency Model}

Prior to the establishment of the fund-raising influence factor model, unit-root test should be carried out as each variables are time series, which may be a not smooth sequence. This paper uses panel data unit root test in both cases of homogeneous unit root and heterogeneous unit root, to test the smoothness in time series of the fund-raising integrated technical efficiency (Score1), debt ratio (DR), negotiable-share ratio (NR) and risk factor (Beta). The results obtained show that, at the 5\% significance level, the original sequence of fund-raising efficiency value Score1, risk factor Beta, debt ratio DR and the negotiable-share ratio cannot pass the unit root test, which are non-stationary sequences. After the first difference, the time series of the four variables above pass the unit root test, indicating that the four variables above are integrated of order one, and there may exist co-integration relationship. 
Table 2. Panel unit root test results of variables of fund-raising efficiency

\begin{tabular}{|c|c|c|c|c|c|c|c|c|}
\hline \multirow{2}{*}{ Test Methods } & \multicolumn{2}{|c|}{ Score1 } & \multicolumn{2}{|c|}{ DR } & \multicolumn{2}{|c|}{ NR } & \multicolumn{2}{|c|}{ Beta } \\
\hline & Statistic & Prob. & Statistic & Prob. & Statistic & Prob. & Statistic & Prob. \\
\hline \multicolumn{9}{|c|}{$\mathrm{H}_{0}$ of homogeneous unit root test: each section of the sequence has a unit root } \\
\hline LLC test & -1.6427 & 0.0592 & -1.3548 & 0.0942 & 0.6498 & 0.7598 & -1.5541 & 0.06657 \\
\hline Breitung test & -1.1155 & 0.1498 & -1.2548 & 0.1058 & 1.3189 & 0.8648 & 0.1684 & 0.5268 \\
\hline \multicolumn{9}{|c|}{$\mathrm{H}_{0}$ of heterogeneous unit root test: the sequence of each section contains the unit root } \\
\hline IPS test & -0.9874 & 0.1954 & -0.0587 & 0.4687 & 0.2284 & 0.5621 & -0.5824 & 0.2854 \\
\hline $\begin{array}{c}\text { Fisher-ADF } \\
\text { test }\end{array}$ & 9.1586 & 0.1587 & 6.6784 & 0.3795 & 6.3841 & 0.3258 & 7.7542 & 0.2854 \\
\hline Fisher-PP test & 5.2595 & 0.4621 & 7.2678 & 0.3158 & 0.6684 & 0.9201 & 5.4521 & 0.5054 \\
\hline \multirow{2}{*}{ Test Method } & \multicolumn{2}{|c|}{$\mathrm{D}($ Score 1$)$} & \multicolumn{2}{|c|}{$\mathrm{D}(\mathrm{DR})$} & \multicolumn{2}{|c|}{$\mathrm{D}(\mathrm{NR})$} & \multicolumn{2}{|c|}{$\mathrm{D}($ Beta $)$} \\
\hline & Statistic & Prob. & Statistic & Prob. & Statistic & Prob. & Statistic & Prob. \\
\hline \multicolumn{9}{|c|}{$\mathrm{H}_{0}$ of heterogeneous unit root test: the sequence of each section contains the unit root } \\
\hline LLC test & -3.6592 & 0.0002 & -5.8535 & 0.0000 & -2.7884 & 0.0037 & -7.7583 & 0.0000 \\
\hline Breitung test & -7.8219 & 0.0000 & -2.3125 & 0.0134 & -1.8885 & 0.0354 & -5.8874 & 0.0000 \\
\hline \multicolumn{9}{|c|}{$\mathrm{H}_{0}$ of heterogeneous unit root test: the sequence of each section contains the unit root } \\
\hline IPS test & -4.0213 & 0.0000 & -5.0544 & 0.0000 & -2.2045 & 0.0089 & -6.0984 & 0.0000 \\
\hline $\begin{array}{c}\text { Fisher-ADF } \\
\text { test }\end{array}$ & 22.5874 & 0.0008 & 29.7855 & 0.0000 & 17.0575 & 0.0098 & 34.0642 & 0.0000 \\
\hline Fisher-PP test & 40.6875 & 0.0000 & 32.7548 & 0.0000 & 18.9457 & 0.0097 & 41.0823 & 0.0000 \\
\hline
\end{tabular}

\section{3) Co-Integration Test of Fund-Raising Efficiency Model and Model Selection}

Panel unit root test indicates the single integration of the same order between fund-raising efficiency, debt ratio, negotiable-share ratio and risk factors in cross-section and time series, thus the co-integration test is available. The co-integration test can verify the existence of long-run equilibrium relationship between the variables, while eliminating spurious regression phenomenon. This paper uses the Kao panel data co-integration test based on EG co-integration test. According to the test results we can conclude, at the 5\% significance level, the statistic value $\mathrm{t}$ of ADF is -3.1254 , with a probability of 0.0008 , and therefore the hypothesis of co-integration null is false, which means there is a significant co-integration relationship between the four groups of variables. To determine the fund-raising efficiency influence factor analysis model, this paper uses Hausman test to determine whether the model is fixed-effect model or random-effect model. The results show that, at the 5\% significance level, the probability is less than 0.05 , rejecting the null hypothesis, and the fixed-effect model should be employed. Then, in the panel data estimation module of Eviews 8.0, we respectively test the individual fixed effects and time fixed effects. The test results show that, at $5 \%$ confidence level, the statistic value $\mathrm{F}$ of the time fixed test is 25.9784 , with a probability of 0.0000 , while the statistics of individual fixed effects also pass the $\mathrm{F}$ test. Therefore, fund-raising efficiency panel regression model is equivalent to time-fixed and individual-fixed effect model.

4) Analysis of efficiency of fund raising

This paper takes the DEA comprehensive measure technical efficiency of fund-raising efficiency as the dependent variable, while the debt ratio DR, negotiable-share ratio NR and risk factor Beta as explanatory variables; it uses generalized least squares method to establish long-term equilibrium model based on panel data, and obtains a residual sequence $E C M_{i t}$. Establish short-term error correction model based on residuals from long-term equilibrium model, and the model parameter estimation results are shown below. At the 5\% significance level, each variable of the long-term equilibrium model have passed the test of significance; the coefficient of determination is 0.8125 , showing the good fitness; F statistic value is 20.3457 , with a probability of 0.0000 ; D-W test value is 1.8648 , within an acceptable range. In the short term, since the coefficient statistics of error correction term $E C M_{i, t-l}$ is significant, the error correction mechanism plays a role in long-term equilibrium. In the error correction model, each variable has passed the test of significance; the coefficient of determination is 0.9084 , the statistic $\mathrm{F}$ is 25.4758 , with a probability of 0.0000 , and the $\mathrm{D}-\mathrm{W}$ test value is 1.8215 , so there is basically no autocorrelation. Therefore, we can see the long-term and short-term impact of financial market behavior on fund-raising efficiency of Guangdong's new energy industries, but with a weak autocorrelation. From the observation of regression coefficients, we can know that whether it is long term or short term, risk factor Beta and negotiable-share ratio NR have positive effect on fund-raising efficiency, while the debt ratio DR has a negative effect. This means that the fund-raising efficiency of new energy listed companies in Guangdong rises with the systematic risk of market; direct financing is in favor of increasing 
fund-raising efficiency, while indirect financing inhibits fund-raising.

Table 3. Estimation results of fund-raising efficiency in panel regression model

\begin{tabular}{ccccc}
\hline \multicolumn{5}{c}{ The Long-Term equilibrium model } \\
\hline Variable & Parameter & Std. Error & t-Statistic & Prob. \\
Beta & 0.1584 & 0.0292 & 5.4284 & 0.0000 \\
DR & -0.1026 & 0.0413 & -2.4869 & 0.0358 \\
NR & 0.2048 & 0.0556 & 3.6847 & 0.0003 \\
\hline \multicolumn{5}{c}{ The Short-Term equilibrium model } \\
\hline Variable & Parameter & Std. Error & t-Statistic & Prob. \\
D(Beta) & 0.2484 & 0.0901 & 2.7574 & 0.0246 \\
D(DR) & -0.4528 & 0.1206 & -3.7541 & 0.0001 \\
D(NR) & 0.6284 & 0.1388 & 4.5278 & 0.0000 \\
ECM & -1.2894 & 0.0335 & -38.4781 & 0.0000 \\
\hline
\end{tabular}

\subsection{Capital Allocation Efficiency and Influence-Factors}

\section{1) Measurement Analysis on DEA Efficiency of Capital Allocation}

According to the features of capital allocation, this paper employs output-oriented DEA model while measuring the capital allocation efficiency of the new energy listed companies in Guangdong Province. Through the analysis of BCC model in MAXDEA6 software, we can obtain capital allocation efficiency of the new energy listed companies measurement results as summarized in the following table. Overall, the average comprehensive technical capital allocation efficiency of the 32 new energy listed companies is 0.759 , with the maximum value of 1 and the minimum value of 0.478 . In terms of the overall trend, the overall efficiency value decreases from a higher point, and then increased gradually. We can see the efficiency of capital allocation Guangdong's new energy industries is not stable, affected by the financial market. Similarly, the favorable policies in 2010 and government support helped increase the output of new energy industry in Guangdong Province, and the business creation value and profits improved. Therefore, the comprehensive technology efficiency of capital allocation of the listed new energy companies in Guangdong Province has reached to a high level, and maintained such height for eight quarters. But after 2011, the rapid development of new energy industries caused the relative saturation, so that the performance of the listed new energy companies are affected, and the capital efficiency decreased, reaching its lowest point in the second quarter of 2013. After that, this new energy listed companies keep path with the Guangdong Provincial Government to deepen the reform of financial markets, adjust its industrial structure, continue to develop new energy technologies, promote the ability of business operations and increase business output and performance, which makes the overall efficiency of capital allocation increase gradually, returning to a higher level, and reach the maximum value of 1in the second quarter in 2015. In addition, from a technical perspective, the average of the pure technical efficiency of new energy industries can reach to 0.80 , and the maximum efficiency value of the seven quarters can reach to 1 . Thus, we can see that the new energy companies in Guangdong Province are introducing and developing new technologies, increasing investment in technology areas with greater efforts; to some extent, the prosperity and development of new energy industries already have adequate technical support.

Comparing fund-raising efficiency, we can see that the efficiency of capital allocation of the new energy listed companies in Guangdong Province is more stable, and the volatility is relatively small, so the new energy listed companies in Guangdong have a relatively better financial operation mechanism, which can convert the capital into more productivity. In terms of financing, new energy listed companies in Guangdong are faced with a big problem, so how to solve the problem of financing becomes the current primary task for new energy industries.

Table 4. Guangdong province, the new energy industry capital allocation DEA efficiency value

\begin{tabular}{ccccc}
\hline \multirow{2}{*}{ Time } & \multicolumn{4}{c}{ New Energy Industry } \\
\cline { 2 - 5 } & Integrated Technical Efficiency & Pure Technical Efficiency & Scale Efficiency & Returns to scale \\
\hline 2010Q1 & 1 & 1 & 1 & constant \\
2010Q2 & 0.835678 & 0.929277 & 0.899277 & increasing \\
2010Q3 & 0.981247 & 1 & 0.981247 & increasing \\
2010Q4 & 1 & 1 & 1 & constant \\
\hline 2011Q1 & 0.977606 & 0.984782 & 0.992713 & increasing \\
2011Q2 & 0.795363 & 0.830078 & 0.958178 & increasing \\
\hline
\end{tabular}




\begin{tabular}{ccccc}
\hline $2011 \mathrm{Q} 3$ & 1 & 1 & 1 & constant \\
2011Q4 & 0.821606 & 0.980747 & 0.837735 & increasing \\
\hline $2012 \mathrm{Q} 1$ & 0.533994 & 0.542447 & 0.984417 & decreasing \\
2012Q2 & 0.531112 & 0.537755 & 0.987645 & decreasing \\
2012Q3 & 0.550527 & 0.568744 & 0.967969 & decreasing \\
2012Q4 & 0.687853 & 0.714645 & 0.962511 & decreasing \\
\hline $2013 \mathrm{Q} 1$ & 0.480403 & 0.525064 & 0.914941 & decreasing \\
$2013 \mathrm{Q} 2$ & 0.478498 & 0.525854 & 0.909944 & decreasing \\
$2013 \mathrm{Q} 3$ & 0.551055 & 0.603233 & 0.913503 & decreasing \\
$2013 \mathrm{Q} 4$ & 0.724097 & 0.765409 & 0.946026 & decreasing \\
\hline $2014 \mathrm{Q} 1$ & 0.588568 & 0.634165 & 0.928098 & decreasing \\
$2014 \mathrm{Q} 2$ & 0.589826 & 0.643625 & 0.916413 & decreasing \\
$2014 \mathrm{Q} 3$ & 0.641639 & 0.710203 & 0.903459 & decreasing \\
$2014 \mathrm{Q} 4$ & 0.89667 & 1 & 0.89667 & increasing \\
\hline $2015 \mathrm{Q} 1$ & 0.958128 & 1 & 0.958128 & increasing \\
$2015 \mathrm{Q} 2$ & 1 & 1 & 1 & constant \\
$2015 \mathrm{Q} 3$ & 0.670805 & 0.716134 & 0.936703 & decreasing \\
$2015 \mathrm{Q} 4$ & 0.918076 & 0.987658 & 0.929549 & decreasing \\
\hline
\end{tabular}

\section{2) Unit Root Test of Variables in Allocation Efficiency Model}

Similarly, before establishing the capital allocation efficiency influence-factor analysis model, we use panel data unit root test in both cases of homogeneous unit root and heterogeneous unit root, to test the smoothness in time series of the fund-raising integrated technical efficiency (Score2), risk factor (Beta), debt ratio (DR) and negotiable-share ratio (NR). The unit root test results of the original sequence of each variable and that after the first difference are shown in the table below. The results obtained show that, at the 5\% significance level, the original sequence of fund-raising efficiency value Score2, risk factor Beta, debt ratio DR and the negotiable-share ratio cannot pass the unit root test, which are non-stationary sequences. After the first difference, the time series of the four variables above pass the unit root test, indicating that the four variables above are integrated of order one, and there may exist co-integration relationship.

Table 5. The panel unit root test results of variables in capital allocation efficiency

\begin{tabular}{|c|c|c|c|c|c|c|c|c|}
\hline \multirow{2}{*}{ Test Methods } & \multicolumn{2}{|c|}{ Score2 } & \multicolumn{2}{|c|}{ DR } & \multicolumn{2}{|c|}{ NR } & \multicolumn{2}{|c|}{ Beta } \\
\hline & Statistic & Prob. & Statistic & Prob. & Statistic & Prob. & Statistic & Prob. \\
\hline \multicolumn{9}{|c|}{$\mathrm{H}_{0}$ of homogeneous unit root test: each section of the sequence has a unit root } \\
\hline LLC Test & -0.6177 & 0.4387 & -1.8527 & 0.0841 & 0.6874 & 0.7215 & -2.8854 & 0.06841 \\
\hline Breitung Test & -1.3255 & 0.1512 & -1.2125 & 0.1624 & 1.3549 & 0.8845 & 0.1542 & 0.5698 \\
\hline \multicolumn{9}{|c|}{$\mathrm{H}_{0}$ of heterogeneous unit root test: the sequence of each section contains the unit root } \\
\hline IPS Test & 0.1584 & 0.5285 & -0.04587 & 0.5941 & 0.2015 & 0.5741 & -0.6315 & 0.2541 \\
\hline Fisher-ADF Test & 4.2568 & 0.7451 & 6.5874 & 0.4215 & 6.2548 & 0.3845 & 7.9541 & 0.3062 \\
\hline Fisher-PP Test & 3.2568 & 0.8121 & 7.6584 & 0.2695 & 0.6415 & 0.9741 & 5.841 & 0.4251 \\
\hline \multirow{2}{*}{ Test Methods } & \multicolumn{2}{|c|}{$\mathrm{D}($ Score 2$)$} & \multicolumn{2}{|c|}{$\mathrm{D}(\mathrm{DR})$} & \multicolumn{2}{|c|}{$\mathrm{D}(\mathrm{NR})$} & \multicolumn{2}{|c|}{$\mathrm{D}($ Beta $)$} \\
\hline & Statistic & Prob. & Statistic & Prob. & Statistic & Prob. & Statistic & Prob. \\
\hline \multicolumn{9}{|c|}{$\mathrm{H}_{0}$ of homogeneous unit root test: each section of the sequence has a unit root } \\
\hline LLC Test & -2.8594 & 0.0069 & -1.8527 & 0.0000 & -2.6684 & 0.0026 & -6.7584 & 0.0000 \\
\hline Breitung Test & -8.5214 & 0.0000 & -1.2125 & 0.0124 & -1.7589 & 0.0134 & -5.2472 & 0.0000 \\
\hline \multicolumn{9}{|c|}{$\mathrm{H}_{0}$ of heterogeneous unit root test: the sequence of each section contains the unit root } \\
\hline IPS Test & -3.5214 & 0.0012 & -5.9541 & 0.0000 & -1.2055 & 0.0068 & -8.0965 & 0.0002 \\
\hline Fisher-ADF Test & 16.5442 & 0.0036 & 26.8455 & 0.0005 & 13.2588 & 0.0231 & 35.8641 & 0.0004 \\
\hline Fisher-PP Test & 12.6845 & 0.0026 & 34.4581 & 0.0006 & 12.2655 & 0.0003 & 38.7581 & 0.0001 \\
\hline
\end{tabular}

\section{3) Co-Integration Test of Capital Allocation Efficiency Model and Model Selection}

The panel unit root tests show the same order integration relationship in the capital allocation efficiency, the risk factor, debt ratio and negotiable-share ratio in cross-section and time series, so we can carry out the co-integration test. In this paper, we use the data co-integration test based on Kao panel co-integration test of E-G co-integration test. According to the test results, we can conclude that at the 5\% significance level, the statistic $\mathrm{t}$ of $\mathrm{ADF}$ is 3.5481 , with a probability of 0.0005 , abandoning the former co-integration null hypothesis, which shows that there is a significant co-integration relationship between the four groups of variables. In order 
to determine the capital allocation efficiency influence-factor analysis model, we use Hausman test to examine the fixed effects of the mode. Test results show that, at $5 \%$ confidence level, the probability is 0 , which abandons the former hypothesis. Then the fixed-effect model should be used. At the same time, in the panel data estimation module of Eviews 8.0, we test the time fixed effects and individual fixed effects. The test results show that, at 5\% confidence level, the statistic $\mathrm{F}$ of time fixed effects is 8.9456 , with the probability close to 0 , while the statistic $\mathrm{F}$ of individual fixed effects also passes the test, with the probability of 0 . Therefore, the capital allocation efficiency panel regression model is equivalent to the time-fixed and individual-fixed effect model.

4) Analysis of Influence Factors in Capital Allocation Efficiency

This paper takes the DEA comprehensive measure technical efficiency of capital allocation efficiency as the dependent variable, while the debt ratio DR, negotiable-share ratio NR and risk factor Beta as explanatory variables; it establishes a long-term equilibrium model, and obtains a residual sequence $E C M_{i t}$. Due to the co-integration relationship between the variables, we introduce the residual sequence as an error correction term to establish short-term error correction model. The regression results are shown in the table below. At the 5\% significance level, the coefficients of all the variables in the long-term equilibrium model and short-term error correction models have passed the significance test, and the determination coefficients of the two models were 0.8832 and 0.9125 , the value of statistic $\mathrm{F}$ were 13.6487 and 18.9451 , with the probability of 0.0000 , and the $\mathrm{D}-\mathrm{W}$ test values were 1.9487 and 1.8549 , which are in a reasonable range. Overall, the results show that the explanatory variables of these two models have strong explanatory power on the dependent variables, but the correlation of model is relatively weak. Thus, we can see the long-term and short-term impact of financial market behavior on capital allocation efficiency of Guangdong's new energy industries. According to the analysis of the coefficients of each independent variable, we can know that whether long-term or short-term, the increase of the risk in Guangdong's new energy listed companies shows negative effects on the capital allocation efficiency for the whole industry; if the debt ratio is too high, it could do harm to capital allocation efficiency. However, the increase of the negotiable-share ratio plays a positive active role in the capital allocation efficiency of Guangdong's new energy industries.

Table 6. Estimation results of capital allocation efficiency in panel regression model

\begin{tabular}{ccccc}
\hline \multicolumn{5}{c}{ The Long-Term equilibrium model } \\
\hline Variable & Parameter & Std. Error & t-Statistic & Prob. \\
Beta & -0.2845 & 0.0789 & -3.6218 & 0.0018 \\
DR & -0.3051 & 0.1151 & -2.6514 & 0.0154 \\
NR & 0.2481 & 0.0772 & 3.2157 & 0.0048 \\
\hline \multicolumn{5}{c}{ The Short-Term equilibrium model } \\
Variable & Parameter & Std. Error & t-Statistic & Prob. \\
D(Beta) & -0.5016 & 0.0571 & -8.7841 & 0.0000 \\
D(DR) & -0.5638 & 0.2124 & -2.6541 & 0.0143 \\
D(NR) & 0.3541 & 0.1390 & 2.5471 & 0.0245 \\
ECM & -1.2365 & 0.0348 & -35.514 & 0.0000 \\
\hline
\end{tabular}

\section{Conclusion}

There is the scarcity of developmental stability and capacity for risk aversion in the new energy industry of Guangdong. When the economical circumstance fluctuates, fund raising has the same fluctuation, as well as the efficiency of allocation, even results in inefficient situation. Thereof, it indicates that funding scale needs to be expanding and financing channel needs to be broadening while payment for fund raising has a progressive increase; at the same time, the efficiency of fund allocation has a progressive decrease, accounting for inefficiency about company development and fund using, maybe there is an overuse or vacancy situation in the process of fund allocation. In addition, because the new energy industry in Guangdong has been developing quickly in the near future, the same as the level of modern technology, it promotes the efficiency for fund raising and allocating and supports the development of industry. But it also exists a financing barrier that blocks the new industry development, it narrows down the financing channel, over-enhances financing cost, makes process complicated which would lead enterprises scale diminished and inefficient.

The efficiency of the financial support can be divided into two stages, the efficiency of fund raising and fund allocating. The efficiency of fund raising reflects the capacity in public company whether it can raise fund to support enterprise operation by the fewest cost. While the efficiency of fund allocation matches public companies within the new industry whether they can exert the optimization by allocating fund reasonably. 
Through some analysis for what influenced the efficiency of financing support, as we can know, within the long-term or short-term, there has a seemingly same effect toward fund raising and allocating among the liability ratio, proportion of outstanding shares and marketing risk.

In the long-term and short-term, there are three financing elements in market orientated, that are the conduct of direct financing, indirect financing and marketing risk, which have a vital influence on the fund raising and allocating in the new energy industry of Guangdong. In terms of fund raising, the proportion of outstanding shares and marketing risk are both positive for the efficiency of fund raising whatever in short-term or in the long-term; moreover, the proportion of outstanding shares has more apparent positive supporting effects. However, the enhance of liability ratio would have a negative impact toward the efficiency of fund raising in the short-term, but it can be weakened if the time admits. Furthermore, in terms of fund allocating, whatever in short-term or in the long-term, the liability ratio and marketing risk both have a negative effect in it, and this type of impact will more severe in the short-term; contrast to the proportion of outstanding shares plays a positive role. Therefore, if we act on direct financing, it can promote the efficiency of fund raising and allocating efficiently, consequently boost the efficiency of financial support of the new energy industry in Guangdong.

\section{References}

Feng, X., \& Wenhao, Z. (2014). The Performance Evaluation of Financial Support for New Energy Industry Based on DEA and Logit Methods. Science and Technology Management Research, (20), 33-38. https://doi.org/10.3969/j.issn.1000-7695.2014.20.008

Feng, X., \& Yongyang, C. (2014). Resaerch on the Efficiency of Banking Support for the Development of the Low-carbon Industry in China Based on the DEA Method. Science and Technology Management Research, (21), 233-237. https://doi.org/10.3969/j.issn.1000-7695.2014.21.045

Fuyou, L., \& Haifeng, Y. (2014). An Empirical Research on Financial Support for the Development of Strategic Emerging Industries based on Granger Test and Co-integration Analysis. Science \& Technology Progress and Policy, (15), 53-58. https://doi.org/10.3969/j.issn.1001-148X.2003.05.039

Hai, F. (2010). Study on the Conduction Mechanism and Path of Financial Support Industrial Structure Adjustment. Securities Market Herald, (9), 27-33.

Hongchan, L., \& Shuai, Y. (2013). Financial Support and Policy Orientation in the Development of Strategic Emerging Industries. Modern Economic Research, (1) 60-3. https://doi.org/10.3969/j.issn.1009-2382.2013.01.013

Jingsi, C. (2010). The State Council Determine Seven Strategic Emerging Industries: Set Up Special Funds, Increase Fiscal and Tax Support. Eastern Morning Post.

Junwei, M. (2013). Research on the Efficiency of Financial Support Efficiency and its Influencing Factors of Seven Strategic Emerging Industries in China - Based on Empirical Evidence from Listed Companies. Reform of Economic System, (3), 133-137.

Mata, J., \& Machado, J. A. F. (1996). Firm Start-up: A Conditional Quantile Approach. European. Economic Review, 40(6), 1305-1323. https://doi.org/10.1016/0014-2921(95)00034-8

Munan, Z. (2009). "Strategic Mapping" to Build a New Energy Finance System. Development Research, (4), 62-64. https://doi.org/10.3969/j.issn.1003-0670.2009.04.018

Schreft, S. L., \& Smith, B. D. (1998). The Effects of Open Market Operations in a Model of Intermediation and Growth. Review of Economic Studies, 48(3). https://doi.org/10.1111/1467-937X.00056

Shihong, Z., GuoSong, H., \& Xin, D. (2011). A Study on Financial Support for Energy-Saving and New Energy Industry. Journal of Southwest Petroleum University (Social Sciences Edition), (2), 1-4, 8. https://doi.org/10.3863/j.issn.1674-5094.2011.02.001

Xianling, J., Yan, W., \& Dongkai, L. (2010). Analysis of Financial Support Path in the Development of New Energy Industry. Economic Review, (8), 50-53.

Xiaoni, Y., Guohong, W., \& Xiaohui, F. (2015). An Empirical of the Influencing Factors on Financial Support of New Energy Industry. Journal of Industrial Technological Economics, (11), 12-18. https://doi.org/10.3969/j.issn.1004-910X.2015.11.002

Xiping, Z., Xiangyu, X., \& Yin, C. (2009). Financial and Policy Support in the Development and Utilization Process of China's New Energy. Journal of Jiangnan Social University, (2), 14-18. https://doi.org/10.3969/j.issn.1673-1026.2009.02.004 
Xuemei, Z. (2014). Analysis of Financial Support Efficiency for Strategic Emerging Industries in Anhui Based on DEA Mode. The Journal of Shandong Agriculture and Engineering University, (6), 56-58. https://doi.org/10.3969/j.issn.1008-7540.2014.06.024

Yuxi, Z. (2006). The Research on Financial Supporting System of Industrial Policy in China. Harbin Engineering University. https://doi.org/10.7666/d.y937093

Zengyi, S., \& Zongyi, Z. (2003). An Empirical Analysis of the Financing Efficiency of Listed Companies. Commercial Research, (5), 97-100. https://doi.org/10.3969/j.issn.1001-148X.2003.05.039

Zhongming, T., \& Zhanqi, L. (2012). A Study of Financial Support Measures for the Development of Strategic Emerging Industries. Enterprise Economy, (2), 172-175. Retrieved from http://www.cnki.com.cn/Article/CJFDTotal-QUIT201202045.htm

\section{Copyrights}

Copyright for this article is retained by the author(s), with first publication rights granted to the journal.

This is an open-access article distributed under the terms and conditions of the Creative Commons Attribution license (http://creativecommons.org/licenses/by/4.0/). 